\title{
Enhance the Activities of Hydrogen Production by Changing the Sequence of Preparation the Ternary Composite $\mathrm{Pt}-\mathrm{TiO}_{2} / \mathrm{MWNT}$
}

\author{
Firas H. Abdulrazzak ${ }^{1 *}$ Falah H. Hussein ${ }^{2}$ \\ ${ }^{1}$ Chemistry Department, College of education for pure science, Diyala University, Diyala, Iraq \\ ${ }^{2}$ Chemistry Department, College of Science, Babylon University, Hilla, Iraq \\ * Corresponding author. Email: firas_habeb2000@yahoo.com
}

\begin{abstract}
Two types of ternary Pt-TiO $/$ /MWNT were synthesized by Sonochemical/HydrationDehydration methods which include photoplatinazation and supporting with MWNTs. The synthesized materials $\left(\mathrm{Pt}-\mathrm{TiO}_{2}\right) / \mathrm{MWNT}$ and $\mathrm{Pt}-\left(\mathrm{TiO}_{2} / \mathrm{MWNT}\right)$ were characterized by X-ray diffraction, Raman spectroscopy, UV-Vis diffuse reflectance spectroscopy, scanning electron microscopy and transmission electron microscopy. The activity of $(0.65 \mathrm{~g} / \mathrm{L}) \mathrm{MWNT} / \mathrm{TiO}_{2} / \mathrm{Ptwere}$ estimated by $\mathrm{H}_{2}$ production from $(7.5$ vol \%) aqueous methanol solution. The results showed that platinizationof $\mathrm{TiO}_{2}$ than create hybrid with MWNTs was more efficient in hydrogen production than platinazationofMWNT/ $\mathrm{TiO}_{2}$. The preparation method, homogenous distribution and localized of MWNTs with Pt onto $\mathrm{TiO}_{2}$ shows sensitively influence in the achieving the best efficient charge separation and transfer in exist the platinum under UV- light $(<420 \mathrm{~nm})$ irradiation.
\end{abstract}

Keywords: MWNT, $\mathrm{TiO}_{2}$; Hydrogen Production; Ternary composite; Sequences of Preparation

\section{1-Introduction:}

The use of nanotechnology in the field of energy aims to provide energy with taking care on the source of energy, cost, and environmental risks as well as get the maximum amount of energy which can be obtained. Hydrogen gas is an ideal technology of energy for the future to produce clean and friendly sources without any damages for the environmental [Chiari, \&Zecca, 2011]. Hydrogen as sources of energy started with electrolysis of water thus the real orientation towards of sustainable technology for hydrogen production [Hashimoto et al., 2005] was developed for a long time ago. Nanomaterials in pristine or compounds and composites showed positive orientations in this field such semiconductors SC, metals M, and carbon nanotubes CNTs [Chen et al., 2010; Ong et al. 2010]. The binary and ternary composites commonly used for synthesizing catalyst used in hydrogen production reactions. The activities of composites depend on nature of bonding which 
produces maximum value for active sites. The ternary composites represent the ideal case for produce many active sites such $\mathrm{Pt}-\mathrm{TiO}_{2} / \mathrm{CNTs}$. $\mathrm{TiO}_{2}$ is semiconductors with three phases, Rutile, Anatase and Brookite. The first two phases of $\mathrm{TiO}_{2}$ are both in a tetragonal structure and the last type in an orthorhombic [Nadtochenko et al., 2006].Carbon nanotubes CNTs is graphite or graphene sheets rolling from side to side to forming a tubular structure with specific properties such chiral, armchair and zig-zag with nanometer in diameter [Falah et al., 2018]. Carbon nanotubes can be classified two single-walled SWNTs, double walled DWNTs, few walled FWNTs and multi-walled carbon nanotubes MWNTs [Falah et al., 2018]. Pt as noble metals with specific physical and chemical behavior which encourage widely used activation and enhance the activities of semiconductors [Shaoet al., 2010; Stefano et al., 2012]. The ternary composites $\mathrm{Pt}-\mathrm{TiO}_{2} / \mathrm{CNTs}$ were used in many applications such Sensors [Stefano et al., 2012] hydrogen production [Firas et al., 2016] converted agent for CO to $\mathrm{CO}_{2}$ [Lin et al., 2009] degradation of many pollutants [Shih et al., 2017]. The method of synthesized ternary composite technically influences with of preparations methods and the sequence of adding the three materials which rarely studied. This studies concern with the sequences effect for the out- sito addition of Pt and MWNTs in activates of $\mathrm{TiO}_{2}$ towards hydrogen production. $\mathrm{TiO}_{2}$ did not show any activities towards the hydrogen production in alcohol/water solution while existing of CNTs or Pt showed abilities to evolve the $\mathrm{H}_{2}$ gas [Firas et al., 2016]. The results from many literature had shown that exits CNTswith $\mathrm{TiO}_{2}$ increasethe surface area of $\mathrm{TiO}_{2}$. The contact between the surface of the $\mathrm{TiO}_{2}$ particle and CNTs or Pt became one of the most important reasoned to accrue the reaction and increase the rate of reaction. The presence of the CNTs or Pt prevents for the recombination the photoexcited electron [Valentin, 2004]. The effect of $\mathrm{Pt}$ with $\mathrm{TiO}_{2}$ in the reaction of hydrogen production [Ren et al., 2007] was shown more effective than two types of CNTs, which is less activates as compare with $\mathrm{Pt}-\mathrm{TiO}_{2} / \mathrm{MWNT}$. The greater synergic effect of $\mathrm{Pt}-\mathrm{TiO}_{2} /$ MWNT can be related to the better charge transfer between $\mathrm{TiO}_{2}$ and $\mathrm{Pt}$ and best distribution for three materials [Yang et al., 2012]. In this studies, two types of Pt$\mathrm{TiO}_{2} /$ MWNTs were synthesized with changing the sequence of addition which characterized by UV-vis reflectance, X-ray diffraction, Raman spectroscopy, TEM images and BET. Activates were tested by using the hydrogen production reaction form $7.5 \%$ of methanol aqueous solution.

\section{2-Experimental}

\subsection{Materials}

Multi-walled carbon nanotubes MWNTs, were purchased from Aldrich, which fabricated by chemical vapor deposition method. Thepurities of MWNTs 95\% and mode diameter $5.5 \mathrm{~nm}$. The $\mathrm{TiO}_{2}$ sample was purchased from Degussa, Germany $\left(\mathrm{TiO}_{2}-\mathrm{P} 25\right)$ consist of $20 \%$ Rutial and $80 \%$ Anatase. The source of Pt was hexachloro 
platonic (IV) acid hexa hydrate $\left(\mathrm{H}_{2} \mathrm{PtCl}_{6} \cdot 6 \mathrm{H}_{2} \mathrm{O}\right)$ where purchased from Riedel-DeHaen AG, Seelze, Hannover, Germany. Methanol(A.R quality, 99.9\%) was supplied from Hayman, England. The work was done in Institute of Technical Chemistry, Leibniz Universität HannoverlGermany.

\subsection{Preparation of Binary and ternary composite}

$\mathrm{TiO}_{2} / \mathrm{MWNT}$ were prepared by a simple evaporation methodbased on our previous works[Firas et al., 2016a]. Firstly,100mg of MWNTs was treated with $60 \mathrm{ml}$ of mixture $\mathrm{HNO}_{3} / \mathrm{H}_{2} \mathrm{SO}_{4}(1 / 3)$ with the assist of ultra-sonic water bath for $7 \mathrm{~h}$ [Dirk et al., 2010] then washing and drying at $100^{\circ} \mathrm{C}$. The required amount of activated MWNTs was dispersed in $200 \mathrm{ml}$ of distilled water by using ultra-sonic system for 20 min then adding the equivalent amount of $\mathrm{TiO}_{2}$ powder which produces $\mathrm{TiO}_{2} / 0.5 \% \mathrm{MWNT}$. The suspension was filtered by vacuum evaporator (Rota vapor re121 BUSHI 461 water Bath) at $45{ }^{\circ} \mathrm{C}$, then dried overnight in an oven at $100{ }^{\circ} \mathrm{C}$. $\mathrm{TiO}_{2}$ was platinized, by photo-depositionmethodwhenmixture of $37 \%$ formaldehyde: absolute ethanol (4:1) was added to the aqueous suspension of $\mathrm{TiO}_{2}$ and an equivalent amount of $\left(\mathrm{H}_{2} \mathrm{PtCl}_{6} \cdot 6 \mathrm{H}_{2} \mathrm{O}\right)$ [ Falah et al., 2016]. The deposition was accrued with UV light irradiated for 3 hour at $40^{\circ} \mathrm{C}$, using a $200-\mathrm{W}$ mercury lampto produce $0.5 \% \mathrm{Pt}$ $\mathrm{TiO}_{2}$. Two types of ternary composites were prepared: the first $(0.5 \% \mathrm{Pt}-$ $\left.\mathrm{TiO}_{2}\right) / 0.5 \% \mathrm{MWNT}$, while the second $0.5 \% \mathrm{Pt}-\left(\mathrm{TiO}_{2} / 0.5 \% \mathrm{MWNT}\right)$. The first ternary composite $\left(0.5 \% \mathrm{Pt}-\mathrm{TiO}_{2}\right) / 0.5 \% \mathrm{MWNT}$ was prepared by platinized the $\mathrm{TiO}_{2}$ then loaded with MWNTs under the same conditions of preparation. The second composite $0.5 \% \mathrm{Pt}-\left(\mathrm{TiO}_{2} / 0.5 \% \mathrm{MWNT}\right)$ was prepared by loaded MWNTs than platinized process.

\subsection{Hydrogen production}

The activity of the composites was evaluated by $\mathrm{H}_{2}$ production from $70 \mathrm{ml}$ of an aqueous methanol solution $(7.5 \mathrm{vol} \%)$ with $(0.65 \mathrm{~g} / \mathrm{L})$ of catalyst which was stirred in a Pyrex-glass reactor (ca. $110 \mathrm{ml}$ volume) equipped with a quartz disc for light penetration. Before to irradiation, Argon gas was purged through the suspension for $30 \mathrm{~min}$. A solar simulator equipped with (SUX 1450) Xenonlampenversorg UNG, Muller, was used as a light source. To avoid thermal effects, the reactor was cooled to room temperature with a cooler system Land Nds. Uni Han. During irradiation, the headspace gas $(40 \mathrm{ml})$ of the reactor was intermittently sampled $(0.5 \mu \mathrm{L})$ and analyzed for $\mathrm{H}_{2}$ using a gas chromatograph (Shimadzu GC - 8A) equipped with a thermal conductivity detector and a carboxen 1000 packed column. 


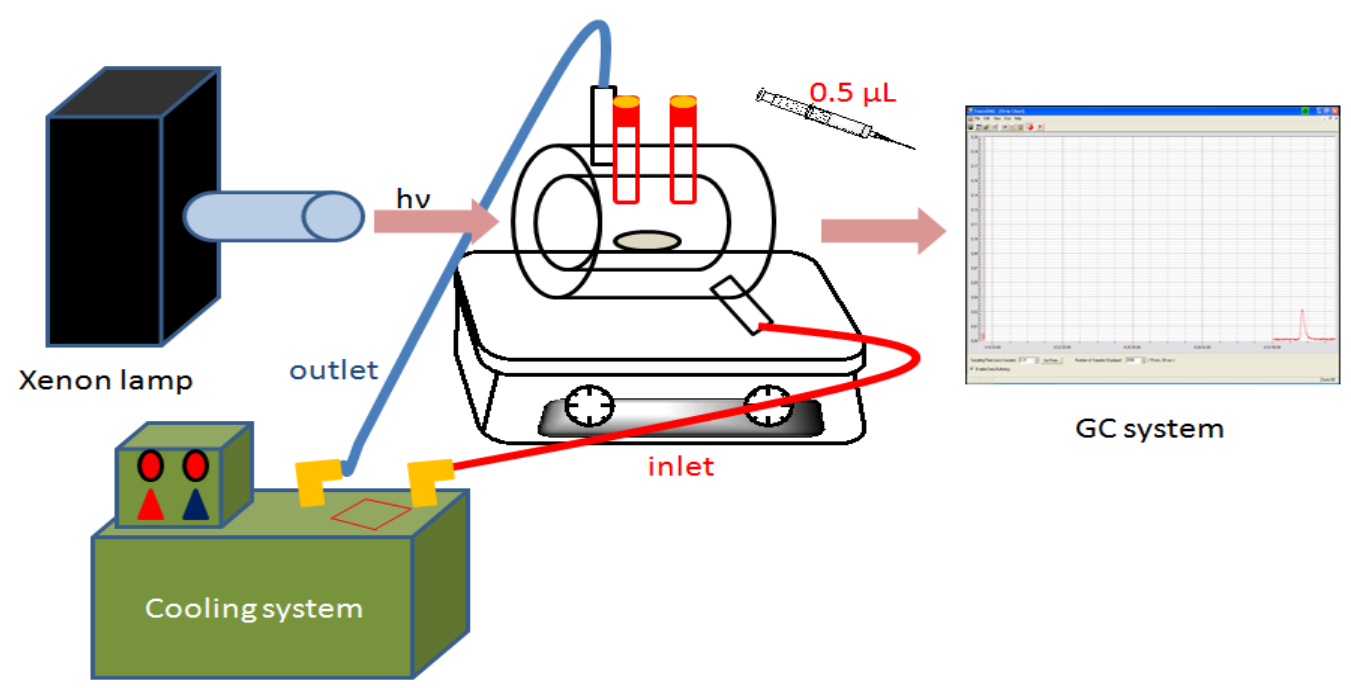

Figure 1. Schematic diagram for the system of hydrogen production

\subsection{Characterization}

UV-Vis diffuse reflectance spectra were recorded over the range of 200-800nm in the absorption mode using a CARY 100 Bio UV-vis spectrophotometer which calibrated with $\mathrm{BaSO}_{4}$. Kubelka-Munk function [Kauffman \& Star, 2008] were depend to calculate the band gap energy $\left(E_{g}\right.$ ) from diffuse reflectance data. The $E_{g}$ value was determined using the theory of optical absorption for allowed direct transitions: $\left\{\mathrm{h} v=\mathrm{A}\left(\mathrm{h} v-\mathrm{E}_{\mathrm{g}}\right)^{1 / 2}\right\}$ where $\mathrm{A}$ is the absorption coefficient which relative to the material, (hv) is the discrete photon energy. The linear portion of extrapolating $(\mathrm{FR} \times \mathrm{h} v)^{1 / 2}$ vs. $\mathrm{h} v$ curves to $\mathrm{FR}=0$ refer to the $\mathrm{E}_{\mathrm{g}}$ as reported in Fig. 2. The important consideration for $\mathrm{TiO}_{2}$ was absorbance occurred at $380 \mathrm{~nm}$, while MWNTs observed broad peaks between 450-1000 nm [Firas, 2016b,c]. In the same time the combined effect of both carbon nanotubes and $\mathrm{Pt}$ in the band gap value of $\mathrm{TiO}_{2}$ will increased[Luma et al., 2014]. Surface area estimation of the $\mathrm{TiO}_{2}$ has been performed by the Brunauer-Emmett-Teller method, performed on a Micrometrics Automate 23 apparatus. The samples have been previously heated to $125{ }^{\circ} \mathrm{C}$ for $30 \mathrm{~min}$ to remove possible contaminants and humidity adsorbed on their surfaces. The measurements have been performed using a gas mixture containing 30 $\%$ nitrogen and $70 \%$ helium as shown in table 1. 
Table 1. Summaries of, surfaces area, particle size and band gap, for pure $\mathrm{MWNTs}, \mathrm{TiO}_{2}$, and modified $\mathrm{TiO}_{2}$ with Pt and MWNTs.

\begin{tabular}{|c|c|c|c|}
\hline Samples & BET $\left(\mathrm{m}^{2} / \mathrm{g}\right)$ & Particle size $(\mathrm{nm})$ & Band gap (e v) \\
\hline MWNT & 282 & 04.37 & 0.50 \\
\hline $\mathrm{TiO}_{2}$ & 51 & 23.09 & 3.18 \\
\hline $\mathrm{TiO}_{2} / 0.5 \% \mathrm{MWNT}$ & 56 & 15.41 & 2.80 \\
\hline $0.5 \% \mathrm{Pt}-\mathrm{TiO}_{2}$ & 47 & 23.13 & 2.75 \\
\hline$\left(0.5 \% \mathrm{Pt}^{-T i O}{ }_{2}\right) / 0.5 \% \mathrm{MWNT}$ & 61 & 18.60 & 2.60 \\
\hline $0.5 \% \mathrm{Pt}-\left(\mathrm{TiO}_{2} / 0.5 \% \mathrm{MWNT}\right)$ & 50 & 25.76 & 2.80 \\
\hline
\end{tabular}

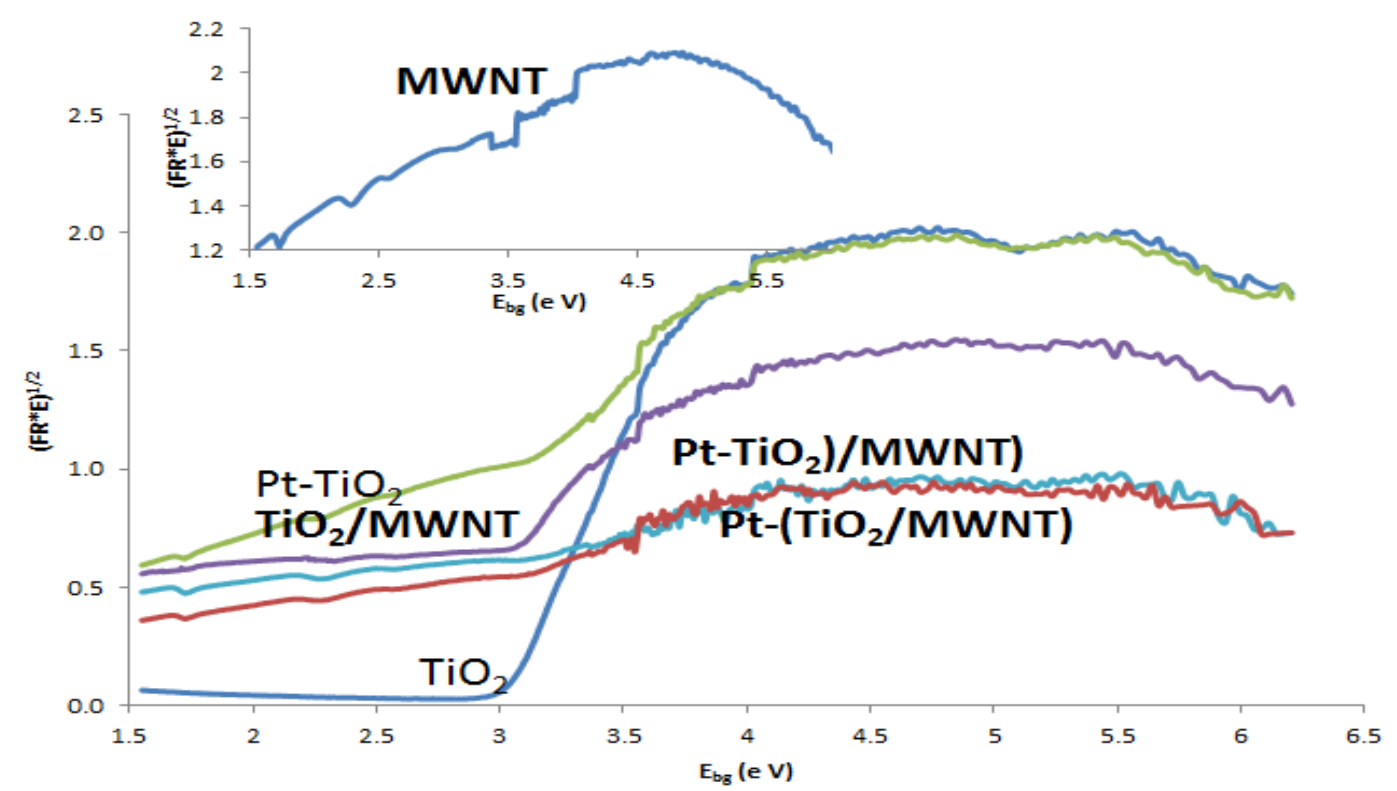

Figure 2. Band gap for pristine and modified TiO2 with MWNTs and Pt in binary and ternary composites.

Table 2. Summaries for activities of binary and ternary composites towards hydrogen productions.

\begin{tabular}{|c|c|c|c|c|c|}
\hline Samples & $r(\mu \mathrm{mole} / \mathrm{h})$ & \multicolumn{2}{|c|}{ Compare ${ }^{* *}$} & $k\left(s^{-1}\right)$ & $\mathbf{R}$ \\
\hline \multirow[t]{2}{*}{$0.5 \% \mathrm{Pt}^{-\mathrm{TiO}_{2}}$} & \multirow[t]{2}{*}{226} & \multicolumn{2}{|c|}{$\mathrm{TiO}_{2}$} & \multirow[t]{2}{*}{4.42} & \multirow[t]{2}{*}{1} \\
\hline & & & Do & & \\
\hline$\left(0.5 \% \mathrm{Pt}^{-\mathrm{TiO}_{2}}\right) / 0.5 \% \mathrm{MWNT}$ & 263 & \multirow{2}{*}{$\stackrel{N}{\dot{v}}$} & \multirow{2}{*}{  } & 4.83 & 1.12 \\
\hline $0.5 \% \mathrm{Pt}-\left(\mathrm{TiO}_{2} / 0.5 \% \mathrm{MWNT}\right)$ & 208 & & & 3.94 & 0.89 \\
\hline
\end{tabular}

The binary and ternary composites were characterized by X-ray diffraction (XRD) on a (RigakuRotalflex) (RU-200B) X-ray diffractometer using $\mathrm{Cu} \mathrm{K} \alpha$ radiation at $0.15405 \mathrm{~nm}$ ) with a Ni filter. The tube current was $100 \mathrm{~mA}$ with voltage $40 \mathrm{kV}$. The 
$2 \theta$ angular regions between 15 and $65^{\circ}$ were explored at a scan rate of $5 \% \mathrm{~min}$. For all XRD tests, the resolution of the $2 \theta$ scans was kept at $0.02^{\circ}$.Fig. 3 shows the XRD patterns of the crystallographic structures of the binary and ternary composites. The influence was limited to the small change in the width of peaks with the shift towards higher $2 \theta$. The $0.5 \% \mathrm{Pt}-\mathrm{TiO}_{2}$, there is only $\mathrm{TiO}_{2}$ in the anatase form and rutile while no peaks of $\mathrm{Pt}$ at $2 \theta=40$ and $48^{\circ}$ can be notes, maybe can be attributed for low ratios of Pt which used or the homogenous dispersion for Pt on TiO2 [Stefano et al., 2012]. Debye-Scherrer equation $(\mathrm{d}=\mathrm{K} \lambda / \beta \cos \theta)$ [Luma et al., 2014] were depended to determine the average crystallite size (d) which estimation by line broadening measurements. When $\lambda$ refers to X-ray wavelength which equals to $0.15405 \mathrm{~nm}, \beta$ is the peak width at half maximum height resulting in radians and $\mathrm{K}$ mostly equal to 0.9 which related to crystallite shape. The peaks at $25.3^{\circ}$ and $27.4^{\circ}$ are the characteristic reflection for anatase and rutile, respectively for $\mathrm{TiO}_{2}$, which did not change in the binary and ternary composite [Stefano et al., 2012]. From Fig. 4, for MWNTs appears two characteristic peaks $2 \theta=25.9^{\circ}$ and $43.2^{\circ}$, from $C(100)$ and $C(002)$ planes of the carbon nanotubes, [Fias et al., 2016a,b].The two peaks for MWNTs disappears in binary and ternary composites because the overlapped for these peaks with the anatase peak of $\mathrm{TiO}_{2}$ at $25.2^{\circ}$ and $43.9 \circ$ [Firas et al., 2016b]. The results show that $\mathrm{TiO}_{2}$ crystallite size of the binary compound did not significantly affect by Pt [Shao et al., 2010] while with MWNTs there is reduces in size. The ternary composite shows the two properties in crystallite size of Pt and MWNTs with $\mathrm{TiO}_{2}$. The two types of ternary composites appear variance in particle size which represent less broadening of the XRD peaks found for $0.5 \% \mathrm{Pt}-\left(\mathrm{TiO}_{2} / 0.5 \% \mathrm{MWNT}\right)$ compared to $\left(0.5 \% \mathrm{Pt}-\mathrm{TiO}_{2}\right) / 0.5 \% \mathrm{MWNT}$. These phenomena make the particle size for pristine and modified $\mathrm{TiO} 2$ arranged as the following: $\mathrm{Pt}-\left(\mathrm{TiO}_{2} / \mathrm{MWNT}\right)>\mathrm{P} 25 \approx \mathrm{P} 25 / \mathrm{Pt}>(\mathrm{Pt}-$ $\left.\mathrm{TiO}_{2}\right) / \mathrm{MWNT}>\mathrm{TiO}_{2} / \mathrm{MWNT}$.

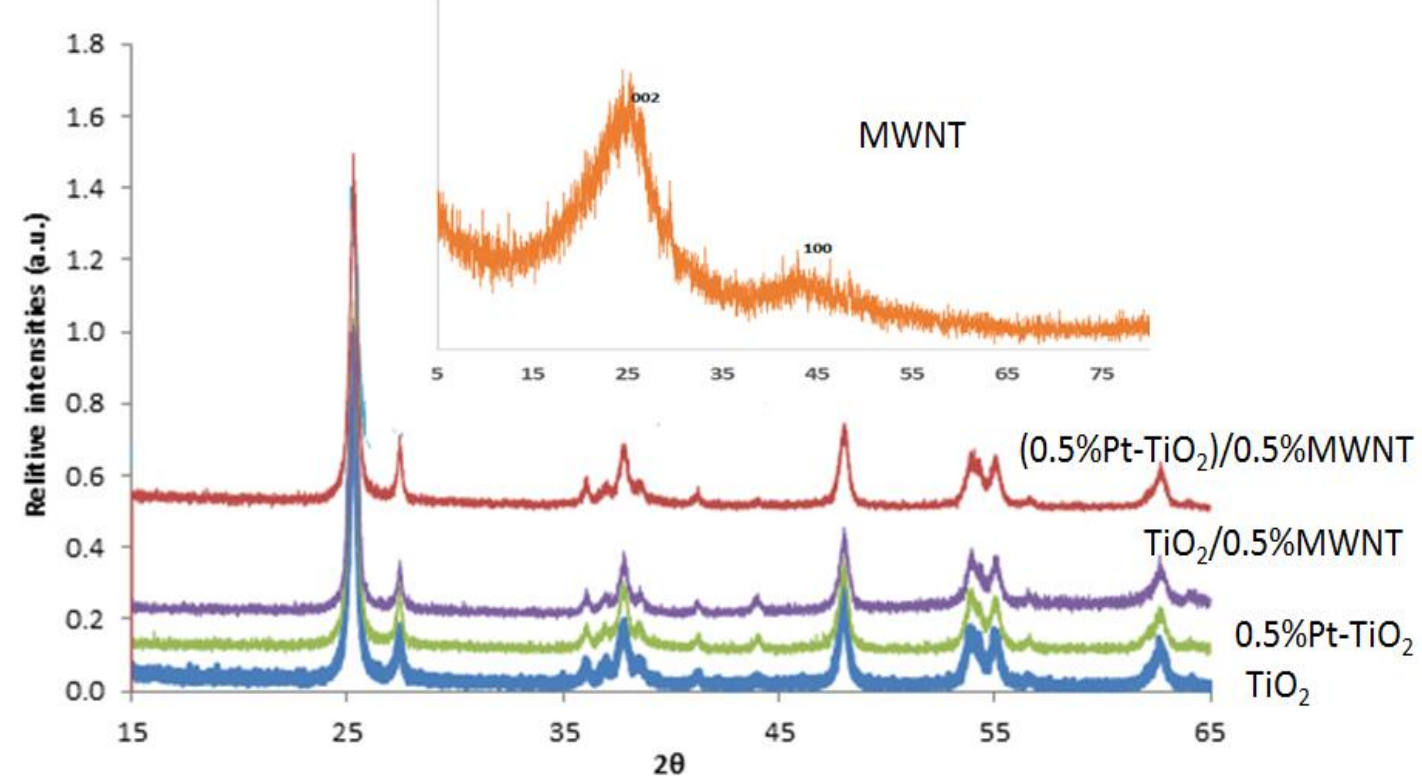


Figure 3. XRD pattern for pristine and modified TiO2 by loading with MWNTs and platinized in binary and ternary composite.

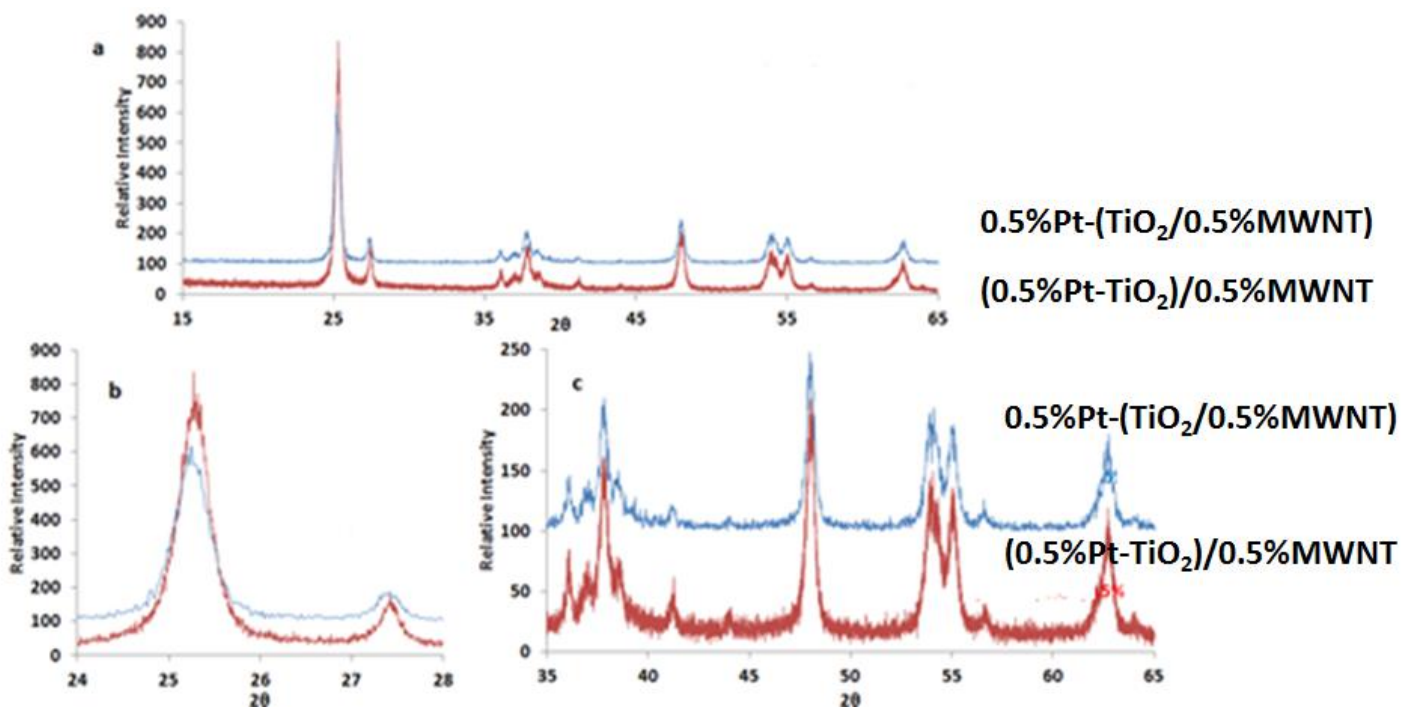

Figure 4. XRD pattern for ternary composite Pt-TiO2/MWNT with different sequence of preparation.

Raman spectroscopy for pure $\mathrm{TiO}_{2}$ was plotted in Fig. 5, characteristic bands for two phases' anatase and rutile. Anatase modes appears at $150 \mathrm{~cm}-1(\mathrm{Eg}), 395.1 \mathrm{~cm}^{-1}(\mathrm{~B} 1 \mathrm{~g}$ ), $512.5 \mathrm{~cm}^{-1}(\mathrm{~A} 1 \mathrm{~g}+\mathrm{B} 1 \mathrm{~g})$ and $636.7 \mathrm{~cm}^{-1}(\mathrm{Eg})$ respectively[Hashimoto et al., 2005 \&Firas et al. 2016a]. rutile phase appears at $143,235 \mathrm{~cm}-1$ which can be ascribed to the B1g, two-phonon scattering, $445 \mathrm{~cm}^{-1} \mathrm{Eg}$, and $612 \mathrm{~cm}^{-1} \mathrm{~A}_{1} \mathrm{~g}$, respectively [Zhenhai et al., 2013].The Raman spectra for both binary and ternary composite with MWNTs showed a G band at $1582 \mathrm{~cm}^{-1}$ corresponding to the wrapped graphene plane and a D band at $1330 \mathrm{~cm}-1$ for the C-related defects of MWNTs [Falah et al.,2018]. In the case of $\mathrm{TiO}_{2} / 0.5 \%$ MWNT composites, all the Raman bands for anatase and MWNTs remain, except slightly broadened. Table 1 and Fig. 5 shows the peak broadening which is consistent with their decease in the average crystallite size. From the Fig.5, it is seen that Raman spectroscopy for $0.5 \% \mathrm{Pt}-\mathrm{TiO}_{2}$, the spectrum shows distortion for $\mathrm{TiO}_{2}$ between $100-700 \mathrm{~cm}^{-1}$ which refer to precipitation $\mathrm{Pt}$ on the surfaces of particles $\mathrm{TiO}_{2}$. The ternary composite shows the two effects for MWNTs and Pt with 


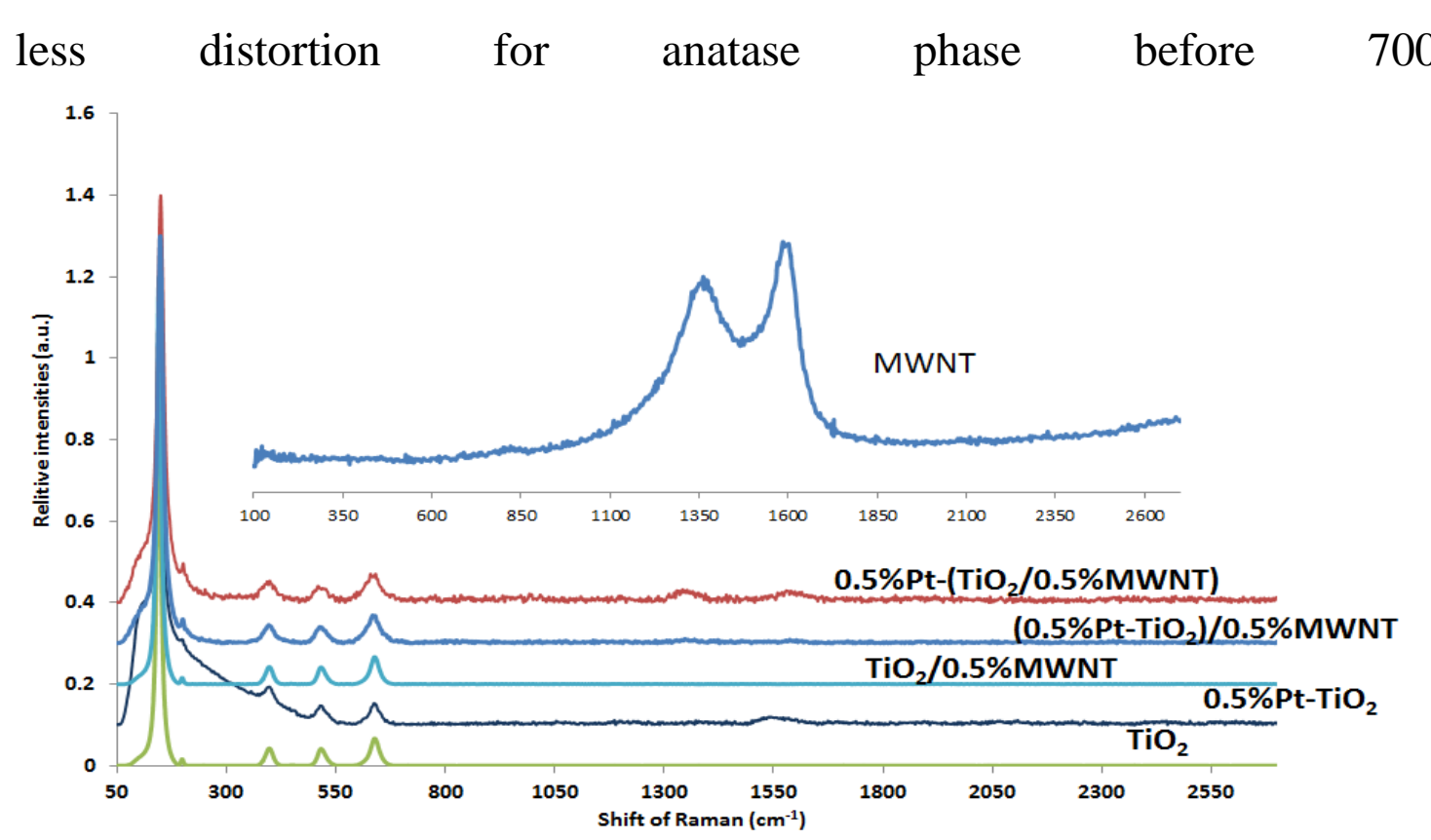

Figure 5. Raman Shift for pristine and modified TiO2 by loading with MWNTs and platinized in binary and ternary composite.

The SEM images in Fig.6(a,b) shows the surface from a $\mathrm{TiO}_{2}$ agglomerate. The marked area is shown in the micrograph to the right at higher magnification, a single carbon fillement is visible. The Fig.6c shows the $\mathrm{TiO}_{2}$ particle surface, which were decorated by a lot of small particles (Platinum) with a single carbon nanotube is visible. The interesting imager which shown in Fig. 6d when seen that particles of $\mathrm{Pt}$ in the surface of CNTs , and that may reffer to the to increasd the activity of ternary composite as compaer with Pt- $\mathrm{TiO}_{2}$.

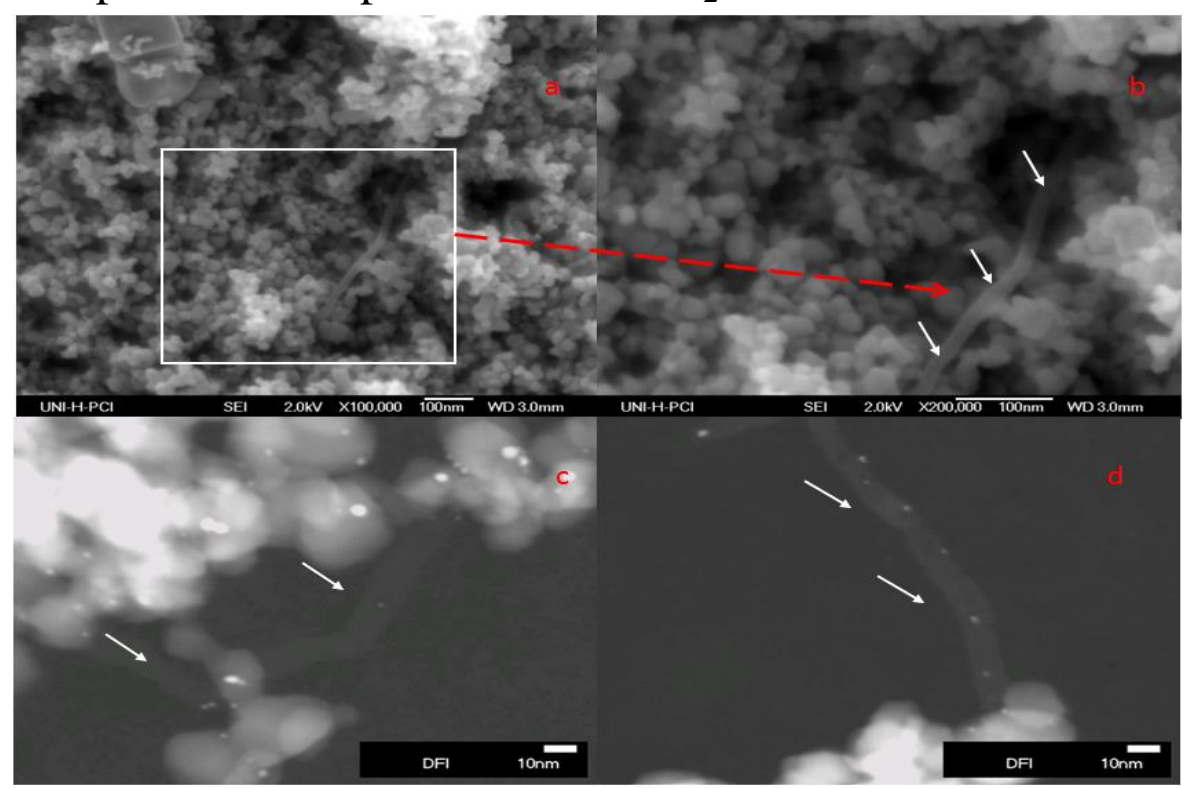

Figure 6. SEM (a,b) and HR-TEM images (c, d) for ternary (Pt-TiO2)/MWNT composites.

\section{3-Results}

The activities of synthesized binary and ternary composites were tested in hydrogen production from 7.5 vol \% aqueous methanol solution. The catalysts include binary 
$\mathrm{TiO}_{2}$ composites which platinized with $0.5 \%$ of Pt or loaded with MWNTs. The last two binary composites were used as control groups against ternary composites. The ternary composites which the aims of this work include two composites with the same ratios and continent but different from each other in the strategy of preparation. The first ternary composite was prepared from platinization of $\mathrm{TiO}_{2}$ than loaded with MWNTs which is $\left(\mathrm{Pt}-\mathrm{TiO}_{2}\right) / \mathrm{MWNT}$. The second ternary composite Pt$\left(\mathrm{TiO}_{2} / \mathrm{MWNT}\right)$ was loaded with MWNTs than platinized. The brackets refer to the first process of preparations and slash refer to support or impregnated surfaces MWNTs while (-) refer to impregnation $\mathrm{Pt}$ onto $\mathrm{TiO}_{2}$. The results were plotted in Fig.7 and listed in table 1 which shows that pristine $\mathrm{TiO}_{2}$ without platinization or loading with MWNTs do not show any activity to produce hydrogen under dark or illumination conditions. The results show that effect of Pt towards hydrogen production was larger than MWNTs in binary composites.

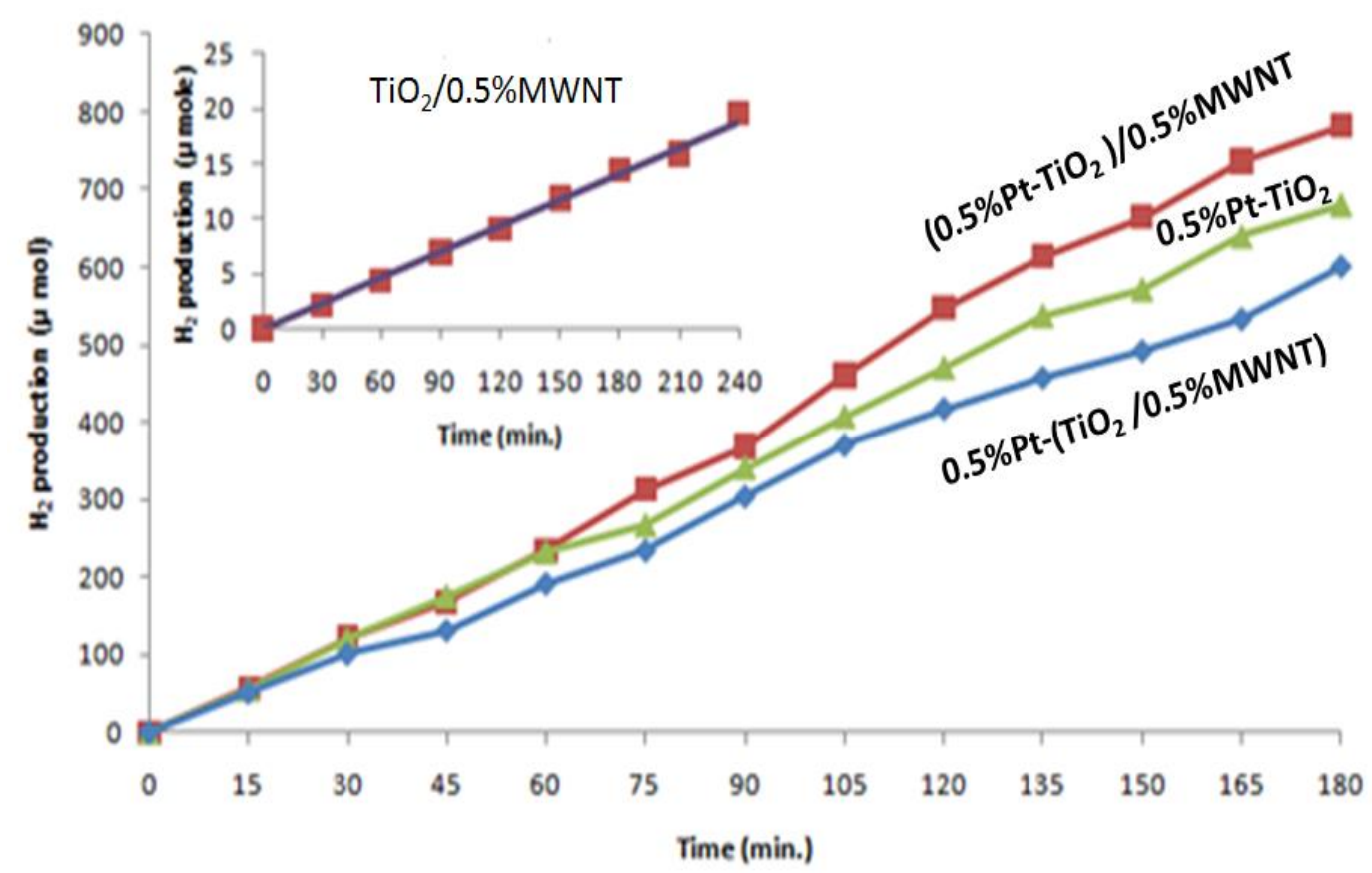

Figure 7. The photocatalytic $\mathrm{H}_{2}$ production from $7.5 \mathrm{vol} \%$ methanol aqueous suspended with $65 \mathrm{mg}$ of Pt-TiO ${ }_{2}, \mathrm{TiO}_{2} / \mathrm{MWNT}$, $\left(\mathrm{Pt}-\mathrm{TiO}_{2}\right) / \mathrm{MWNT}$ and $\mathrm{Pt}-\left(\mathrm{TiO}_{2} / \mathrm{MWNT}\right)$ using $300 \mathrm{~W}$ xenon arc lamp as the light source.

Table 2, shows that ternary composite $\left(\mathrm{Pt}-\mathrm{TiO}_{2}\right) / \mathrm{MWNT}$ was succeeded to increase the hydrogen production more than $\mathrm{Pt}-\mathrm{TiO}_{2}$ while $\mathrm{Pt}-\left(\mathrm{TiO}_{2} / \mathrm{MWNT}\right)$ was failed. The evaluations for the results of hydrogen production in two types of ternary composites compare with binary composites, can estimated synergy factor (R). The increase and reduce were calculated by apparent rate constant for $\mathrm{Pt}-\mathrm{TiO}_{2} / \mathrm{MWNT}$ with $\mathrm{Pt}-\mathrm{TiO}_{2}\{\mathrm{R}$ $\left.=\mathrm{k}_{\mathrm{app}} \mathrm{Pt}-\mathrm{TiO}_{2} / \mathrm{MWNT} / \mathrm{k}_{\mathrm{app}} \mathrm{Pt}-\mathrm{TiO}_{2}\right\}$. The $\mathrm{R}$ represent the best calculus to valuation 
effect of loading MWNTs and platinazation towards achievement maximum activities for hydrogen production.

** These values refer to the rate of hydrogen evaluate for $\mathrm{TiO}_{2} / 0.5 \% \mathrm{MWNT}$ which insert with these tables for compare with the same ratios of $\mathrm{Pt}$ in $\mathrm{Pt}-\mathrm{TiO}_{2}$ and with $\mathrm{Pt}-\mathrm{TiO}_{2} / \mathrm{MWNT}$.

4. Discussion The efficiency of $\mathrm{Pt}-\mathrm{TiO}_{2} / \mathrm{MWNT}$ [Bo et al., 2013] increases with increasing the direct connections between $\mathrm{TiO}_{2}$ and $\mathrm{Pt}$ with interference MWNTs for creating the best transfer of the electrons from $\mathrm{TiO}_{2}$ to methanol/ $\mathrm{H}_{2} \mathrm{O}$ mixture. The strong connections between $\mathrm{TiO}_{2} /$ MWNTs occurred when MWNTs penetrated through $\mathrm{TiO}_{2}$ under the influence of ultrasonic when succeed to break Van Der Waals interaction for MWNTs bundles [Yi et al., 2010]. The results of UV-visible reflectance and XRD refer to change in band gap and particle size which shows variance in size of groups as explain in Figure 8. The activities of $\mathrm{Pt}-\mathrm{TiO}_{2}$ can be related to $\mathrm{Pt}$ when removed photoexcited electron from hole because reduce the space charge [18] and forming Schottky barrier for $\mathrm{TiO}_{2}$ electron in $\mathrm{CB}$ to the $\mathrm{CB}$ of Pt. the role of MWNT in binary $\mathrm{TiO}_{2} / \mathrm{MWNTs}$ was the same action of $\mathrm{Pt}$ with less activities which shows in value of product. The different between Pt- $\mathrm{TiO}_{2}$ and $\mathrm{TiO}_{2} / \mathrm{MWNTs}$ were shown in reducing the agglomerations and increase the surface area with MWNTs as compare with Pt as represented in Fig. 8 and table 2.



Figure 8.Schematics of synthesized -1, (Pt-TiO2)/MWNT, by platinized than loading by MWNTs 2, Pt-(TiO2/MWNT), by loading with MWNT than platinized.

Fig. 8 refer to the behaviors of ternary composites when accumulations for effect of $\mathrm{Pt}$ and MWNTs reduce the surface area SBET for $\left(\mathrm{Pt}-\mathrm{TiO}_{2}\right) / \mathrm{MWNT}$ and increase SBET with Pt-( $\left.\mathrm{TiO}_{2} / \mathrm{MWNT}\right)$. The process of platinization was added many active sites to produce many agglomerations that covered most of the active sites causing reduce the activity. Loading MWNTs within ultra-sonic water bath at least reduce the agglomerations which encourage to shows more active site. All of this change in morphology can be seen in Fig9. When TEM images show redistribution for Pt onto MWNTs and $\mathrm{TiO}_{2}$ surface under the effect of ultra-sonic [Jimmyet al., 2002].The 
ternary composite as mentions before shows variance on activities for evaluating hydrogen gas, which appears as a result of appearing or disappears the active site which responsible for activities.

\subsection{Mechanism of the reaction}

The mechanism depends on transfer of the electrons from $\mathrm{TiO}_{2}$ to MWNTs as mentions in many works of literature [Rowan \& Aidan, 2009] and represents in Fig.9A. When $\mathrm{TiO}_{2}$ was attached to the surface of MWNTs, the active site of the binary matrix within existing of UV lights, mostly stimulates the transfer of excited electrons from the surface of $\mathrm{TiO}_{2}$ to the network of MWNTs [Baoet al., 2012] which become a source to convert $\mathrm{H}^{+}$to $\mathrm{H}_{2}$. The effect of $\mathrm{Pt}$ was more activities for withdrawn the excited electron as compare with MWNTs as represented in Fig.9B.

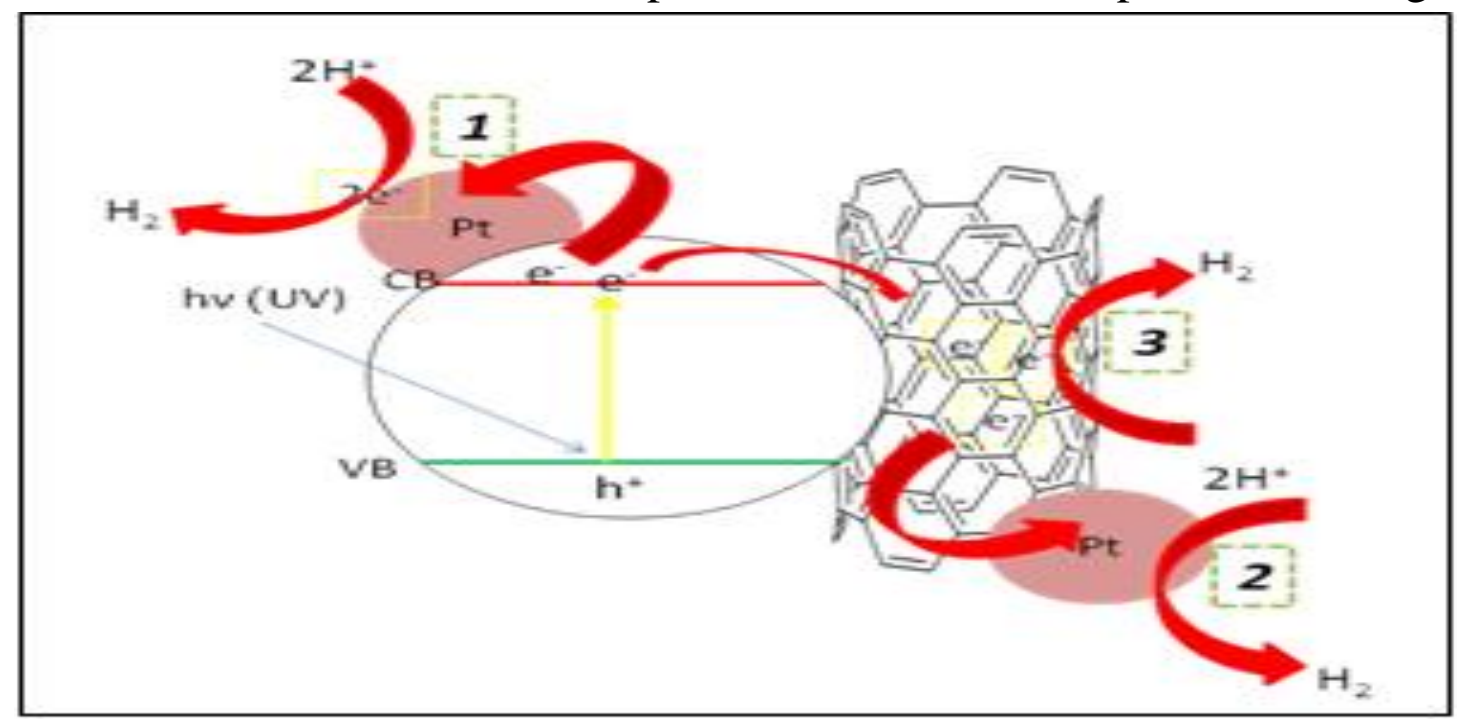

Figure 9.Sckematic diagram for proposal mechanism of A- TiO2/MWNT, and B- Pt-TiO2.

The mechanism depends on transfer of the electrons from $\mathrm{TiO}_{2}$ to MWNTs as mentions in many works of literature [Rowan \& Aidan, 2009]. When $\mathrm{TiO}_{2}$ was attached to the surface of MWNTs, the active site of the binary matrix removed the exited electrons which forming $\mathrm{H}_{2}$ gas. In the cases of Pt- $\mathrm{TiO}_{2} / \mathrm{MWNT}$, under the irradiation the electrons were excited to the conduction band $\mathrm{CB}$ from valence band $\mathrm{VB}$ of $\mathrm{TiO}_{2}$. The Pt- $\mathrm{TiO}_{2} / \mathrm{MWNT}$, raises two routes for electrons to transfer, the first is from the conduction band of $\mathrm{TiO}_{2}$ to $\mathrm{Pt}$, and the second is to transfer the electrons to MWNTs. The second routs appear two probabilities, one of them include indirect ways for transfer the electron to Pt which adsorbed on the surfaces of MWNTs. The ether which represents direct ways from the surfaces of MWNTs to $\mathrm{H}^{+}$and all of this state causing evaluate the hydrogen gas as shown in Fig. 10. The efficiency of Pt$\mathrm{TiO}_{2} / \mathrm{MWNT}$ may relate to the $\mathrm{Pt}$ particles on $\mathrm{TiO}_{2}$ aggregates were isolated the electrons transport which limited in activity by the insufficient local electronic conductivity of $\mathrm{TiO}_{2}$ [Lin et al., 2009]. The UV lights, mostly stimulates transfer of 
excited electrons from the surface of $\mathrm{TiO}_{2}$ to the network of MWNTs [Baoet al., 2012] which become a source to convert $\mathrm{H}^{+}$to $\mathrm{H}_{2}$ as shown in Fig. 10 .


Figure 10. Schematic diagram for the mechanism of ternary composite Pt-TiO2/MWNT.

\section{Conclusion}

The binary and ternary composite was successfully synthesized by using simple evaporations methods and platinazation to forming Pt- $\mathrm{TiO}_{2}, \mathrm{TiO}_{2} / \mathrm{MWNT}$ and Pt$\mathrm{TiO}_{2} / \mathrm{MWNT}$. The ability of Pt to evaluate hydrogen in binary composite was more active than MWNTs although, reduce the activities of Pt- $\left(\mathrm{TiO}_{2} / \mathrm{MWNT}\right)$ when platinazation were done after loading with MWNTs.Ternary composite Pt- (Pt$\mathrm{TiO}_{2}$ )/MWNT showed the best abilities to increase the activities due todouble effectof MWNTs when reduces the agglomeration, and make with $\mathrm{Pt}$ as a bridge to move the electrons from $\mathrm{TiO}_{2}$ freely. Thus chose the best ways for preparations toachieve the ideal transfer of electron can produce the best activities for hydrogen production.

\section{Acknowledgements:}

Detlef W. Bahnemann and I. Ivanova acknowledge financialsupport from the BMBF (BundesministeriumfürBildung undForschung), research projectDuaSol (03SF0482C).

\section{References:}

Bao Y. X., Shujiang D., Hao B. W., Xin W. \&Xiong W. D.(2012). Hierarchically structured Pt/CNT@ $\mathrm{TiO}_{2}$ nanocatalysts with ultrahigh stability for low-temperature fuel cells, RSC Advances, 2,792-796.

Bo C., Tianyou P., Xiaohu Z., Jing M., Kan L. \& Xungao Z.(2013).Synthesis of C60-decorated SWCNTs (C60-d-CNTs) and its TiO2-based nanocomposite with 
enhanced photocatalytic activity for hydrogen production", Dalton Transactions, 42(10), 3402-3409.

Chen X., Shen S., Guo L., \& Samuel S. M. (2010). Semiconductor-based Photocatalytic Hydrogen Generation.Chemical Reviews, 110 (11), 6503-6570.

Chiari, L. \&Zecca A. (2011). A. Constraints of fossil fuels depletion on global warming projections. Energy Policy, 39(9), 5026-5034.

Dirk M. Guldi\& Martín N.(2010). Carbon Nanotubes and Related Structures Synthesis, Characterization, Functionalization, and Applications. WILEY-VCH Verlag GmbH \& Co. KGaA, Weinheim. Kauffman D. R. \& Star A.(2008).Carbon nanotube gas and vapor sensors. AngewandteChemie International Edition, 47,65506570.

Falah H. Hussein, Firas H. Abdulrazzak, and Ayad F. Alkaim, (2018). Nanomaterials: Biomedical and Environmental Applications, chapter 1: Nanomaterials: Synthesis and Characterization, 1 ed. Welly .

Firas H. Abdulrazzak, Falah H. Hussein, Ayad F. Alkaim, Irina Ivanova, Alexei V. Emeline \& Detlef W. Bahnemann. (2016a) Sonochemical /hydration-dehydration synthesis of $\mathrm{Pt}-\mathrm{TiO}_{2} \mathrm{NPs} /$ decorated carbon nanotubes with enhanced photocatalytic hydrogen production activity. Photochemical \&PhotobiologicalSciences., 15(11),1347-1357.

Firas H. Abdulrazzak(2016b). Enhance photocatalytic Activity of TiO2 by Carbon Nanotubes. International Journal of ChemTech Research., 9(3) 431-443.

Firas H. Abdulrazzak, Shahad K Esmail, Halimah A. Dawod, Ahmed M. Abbas \& Mustafa K. K. Almaliki. (2016c).X-ray Analysis for Purification Process of Synthesized Multi-Walled Carbon Nanotubes by Chemical Vapor Deposition. International Journal of Theoretical \& Applied Sciences, 8(1), 432016-432037 .

Hashimoto K., Irie H., \&Fujishima A, (2005). $\mathrm{TiO}_{2}$ photocatalysis: a historical overview and future prospects. Japanese Journal of Applied Physics , 44(12),82698285.

Jimmy C. Yu, Jiaguo Y., Lizhi Z. \&Wingkei H.(2002).Enhancing effects of water content and ultrasonic irradiation on the photocatalytic activity of nano-sized TiO2 powders. Journal of Photochemistry and Photobiology. A: Chemistry, 148,263-271.

Lin K.N., Liou W.J., Yang T.Y., Lin H.M., Lin C.K., Chien S.H., Chen W.C.\& Wu S.H.(2009). Synthesis of hybrid Pt/TiO2 (anatase)/MWNTs nanomaterials by a combined sol-gel and polyol process. Diamond and Related Materials . 18,312-315. Luma M. Ahmed, Irina I., Falah H. Hussein, \&Detlef W. Bahnemann. (2014). Role of Platinum Deposited on $\mathrm{TiO} 2$ in Photocatalytic Methanol Oxidation and Dehydrogenation Reactions. International Journal of Photoenergy.(3):1-9. 
Nadtochenko V., Denisov N., Sarjusiv O., Gumy D., Pulgarin C. \& Kiwi J.(2006). Laser kinetic spectroscopy of the interfacial charge transfer between membrane cell walls of E. coli and TiO2. Journal of Photochemistry and Photobiology A: Chemistry, 181,401-408.

Ong Y. T., Ahmad A.L., Hussein S. Z. \& Soon H. T. (2010). A review on carbon nanotubes in an environmental protection and green engineering perspective. Brazilian Journal of Chemical Engineering

Ren W. J., Ai Z. H., Jia F. L., Zhang L. Z., Fan X. X. \& Zou Z. G. .(2007).Low temperature preparation and visible light photocatalytic activity of mesoporous carbon-doped crystalline TiO2. Applied Catalysis

Rowan L.\& Aidan W.(2009). Carbonaceous nanomaterials for the enhancement of TiO2 Photocatalysis. Diamond and Related Materials

Shao F. C., Jian P. L., Kun Q., Wei P. X., Yang L., Wei X. H. \& Shu H. Y. (2010).

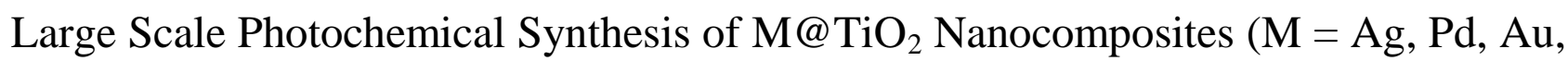
$\mathrm{Pt}$ ) and Their Optical Properties, CO Oxidation Performance, and Antibacterial Effect. Nano Research, 3(4),244-255.

Shih-Y. L., Ya-Chu Y., Sheng-Hsin H., \& Jon-Yiew G.(2017). Synthesis of

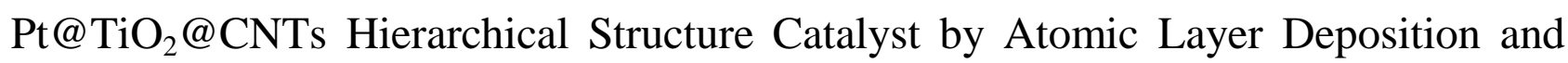
Their Photocatalytic and Photoelectrochemical Activity",Nanomat. (Basel). 7(5)97112.

Stefano T., Andrea D., Mariangela L., Nicola D., Salvatore G. L. \& Giovanni N. (2012). Pt-TiO $/$ MWNTs Hybrid Composites for Monitoring Low Hydrogen Concentrations in Air, Sensors, 12(9), 12361-12373.

Valentin N. P.(2004). Carbon nanotubes: properties and application. Materials Science and Engineering. R, 43, 61-102.

Yang Z, Du G., Meng Q., Guo Z., Yu X., Chen Z., Guo T. \& Zeng R.(2012). Synthesis of uniform TiO2@carbon composite nanofibers as anode for lithium ion batteries with enhanced electrochemical performance. Journal of Materials Chemistry. 22(12), 5848-54.

Yi-Jun X., Yangbin Z. \&Xianzhi F.(2010). New insight for enhanced photocatalytic activity of $\mathrm{TiO} 2$ by doping carbon nanotubes: A case study on degradation of Benzene and Methyl Orange", The Journal of Physical Chemistry. C , 114, 26692676.

Zhenhai W., Suqin C., Shun M., Shumao C., Ganhua L., Kehan Y., Shenglian L.\& Zhen H., Junhong C.(2013).TiO2 nanoparticles-decorated carbon nanotubes for significantly improved bioelectricity generation in microbial fuel cells", Journal of Power Sources. 234, 100-106. 